\title{
Students' perceived self-efficacy, expectations, barriers, and support in enrolling in a master's degree program in respiratory care
}

\author{
Vincent Showalter, MSRC, RRT-RCP1 , Chris Russian, PhD, RRT, RRT-NPS, RPSGT, RST, FAARC ${ }^{1}$, Joshua Gonzales, DHSc RRT-NPS, \\ RRT-SDS ${ }^{1}$, Arzu Ari, PhD, RRT, PT, CPFT, FAARC, FCCP ${ }^{1}$
}

\begin{abstract}
V Showalter, C Russian, J Gonzales, A Ari. Students' perceived self-efficacy, expectations, barriers, and support in enrolling a master's degree program in respiratory care. Can J Respir Ther 2021;57:154-159. doi: 10.29390/cjrt-2021-020.

Background: Respiratory care programs are under pressure to recruit and retain students in both undergraduate and graduate programs. Factors that influence undergraduate students' decisions to continue their education into an advanced degree program are not fully understood. The purpose of this study is to determine students' perceived self-efficacy, outcome expectations, barriers, and support to attend a Master of Science in Respiratory Care (MSRC) program.

Methods: This study used a survey from a previous study that included questions on undergraduate student self-efficacy, outcome expectations, perceived barriers and was utilized to assess students' perceptions of the support to attend an MSRC and its impact on their career goals. Student self-efficacy is defined as a person's beliefs and ability about his/her capacity to succeed in a specific situation. All undergraduate students $(n=89)$ in the Bachelor of Science in Respiratory Care program at Texas State University were invited to participate in the study.

Results: A total of 87 surveys were collected (42 juniors and 45 seniors) with a response rate of $97.7 \%$. Ninety percent of study participants were female, and the average age was $22.54 \pm 3.50$ years. Self-efficacy results indicate that $88.5 \%$ of our undergraduate students believe they would be successful if enrolled in the MSRC program. Only 58.6\% are interested in pursuing the MSRC, possibly because 51.7\% do not think the MSRC is required for the job they want. However, $98.8 \%$ believe the MSRC will create more opportunities for them. Cost (34\%), tired of schoolwork (20\%), and marriage (10\%) are the three main reasons not to attend the MSRC. Of those interested in an MSRC program, $71.3 \%$ reported that they do not know if they can receive financial support for graduate studies, $71 \%$ are unaware of how to contact a graduate program coordinator, and $89 \%$ fear difficulty in navigating graduate school and networking with others.

Conclusion: Respiratory care students have self-efficacy to attend an MSRC program and believe it will provide more opportunities for them. However, cost and resource awareness are the main barriers to enrolling in the graduate program. This study highlights students' perceived barriers and challenges in advancing their knowledge and continuing their education with an MSRC degree and the need for student support.
\end{abstract}

Key Words: respiratory care; students; advanced degree; self-efficacy; expectations; barriers; support; undergraduate and graduate programs

\section{INTRODUCTION}

As the field of respiratory care continues to expand, so do the profession's educational standards. In 2007, the American Association for Respiratory Care (AARC) established a task force to outline respiratory therapy competency standards needed for the workforce in 2015 and beyond. Among their recommendations was the need to advance the profession's educational standards from an associate-level degree to a baccalaureate degree [1]. Today, the profession continues to evolve through the development of Master of Science in Respiratory Care (MSRC) degree programs across the country. In an AARC Human Resources Survey [2], approximately one-third of respondents reported they were motivated to pursue a higher-level degree to access advanced career opportunities. The percentage of respondents who reported they were actively pursuing higher-level degrees also increased from 2014 to 2017 [2]. However, despite significant interest, barriers still exist that prevent some practitioners from pursuing a graduate-level education, such as lifestyle changes and schedule permittance.
One common barrier is understanding the value of an MSRC degree. As a newly established graduate degree, the value of an MSRC may still be unknown to some practitioners. It was previously reported that respiratory care managers perceived a graduate school degree would benefit careers in management, education, or clinical coordinator/specialty [3]. An AARC Human Resources Survey reported that persons in higher-paying occupations, such as directors, supervisors, and educators, typically hold undergraduate and graduate degrees [4]. Despite this, many respiratory therapists do not recognize the need for graduate degrees within their own field. The results of a previous survey reported that $59 \%$ of respondents were considering moving on from the field of respiratory care as they pursued an advanced degree [5].

An additional potential barrier to pursuing an MSRC degree includes the perception of time to complete course requirements. A practicing, full-time therapist might find it difficult to obtain a graduate-level education in a traditional in-person classroom setting. To provide increased accessibility, many graduate programs have chosen to

\footnotetext{
${ }^{1}$ Department of Respiratory Care, Texas State University, Round Rock, Texas

Correspondence: Arzu Ari, Texas State University, Department of Respiratory Care, 200 Bobcat Way, Willow Hall, Suite\# 214 Round Rock, Texas, 78665 , E-mail:arzuari@txstate.edu
}

Published online at https://www.cjrt.ca on 29 November 2021 
deliver their programs in an online, virtual format, which $75 \%$ of respiratory care managers recommended a graduate education be delivered in [3]. Online distance learning programs have become more efficient in content delivery and have evolved to become more interactive. Prospective students who are new to online education may find that advances in distance education have made learning efficient and effective.

The question of motivation may also be a factor in practitioners' pursuit of an MSRC degree. After completing their entry-level programs, many newly graduated respiratory therapists seek immediate employment rather than contemplating pursuing further academic study. Understanding students' perceptions can provide important information on how to support students' needs and increase enrollment into MSRC programs. Previous research in respiratory care education has focused mainly on undergraduate respiratory care programs [6-12], respiratory therapy faculty [13], clinical education [12-16], students' admission [17], retention [18], and success on the national board exams [19-21]. However, students' needs and perceptions should be central in the design, development, and promotion of graduate-level respiratory care education to increase interest and future enrollment. Therefore, the purpose of this study is to determine students' perceived self-efficacy, outcome expectations, barriers, and support pertaining to the MSRC study.

\section{METHODS}

\section{Subjects and sampling}

Using convenience sampling, 89 undergraduate students $(n=89)$ in the Department of Respiratory Care at Texas State University were invited to participate in this study. Eighty-seven students, including 42 juniors and 45 seniors, consented to participate. Two students consented but did not complete the survey. The completion rate of this study is $97.7 \%$.

\section{Ethical considerations}

This study was approved by the institutional review board (IRB) at Texas State University. The survey was completely anonymous, and participation was voluntary.

\section{Research design and instrument}

We distributed a self-report survey to evaluate students' perceived self-efficacy, expectations, barriers, and support in the enrollment to the MSRC at Texas State University. The survey that was utilized in this study was developed by Borrego et al. [22], which included 31 questions with a five-point Likert Scale ranking system $(1=$ Strongly Disagree to $5=$ Strongly Agree). The perceived impact of the MSRC program on students' career goals was also explored. After receiving a written agreement from Borrego et al., we replaced the term "engineering" with "respiratory care" and added questions to capture student demographic information. All modifications were approved by Borrego et al. [22]. The questionnaire package included the cover letter, informed consent, and survey. The survey was validated by Borrego et al. [22] using multiple methods. First, using data obtained from their previous ethnographic study interviews on engineering graduate students, an initial set of Likert-scale items about graduate school decisions was created. Second, Borrego et al. [22] created additional items related to undergraduate students' perceptions about graduate study. Third, content experts reviewed the draft questionnaire and provided suggestions to increase clarity in the survey. Fourth, they conducted a pilot study with 50 undergraduate students to measure internal consistency. The final instrument had an overall Cronbach's alpha of 0.733 .

Data collection and analysis

After receiving IRB approval from Texas State University and informed consent from all participants, the survey was then explained and handed out to the students to be completed. All students took the survey in class at the same time. After the first author of this study introduced the survey to the students, the participants were given $25 \mathrm{~min}$ to complete the survey. When all the surveys were completed, data were entered into the
Statistical Package for the Social Sciences version 24 (SPSS, Chicago, Illinois) for analysis. Descriptive statistics, including median, frequency, and percentage, were calculated for each variable explored in this study.

\section{RESULTS}

Out of the 87 students surveyed, there were 78 females and nine males. No participants identified in any other gender category. The mean age of junior and senior students was 22 and 24 years, respectively. The two largest ethnic groups were Hispanic and Caucasian. Table 1 represents the demographics of students who participated in this research.

Participants' perceived self-efficacy in attending graduate school Table 2 depicts the response data for questions pertaining to students' perceived self-efficacy. Out of those 87 surveyed, $57.5 \%$ believe that their undergraduate education prepared them for graduate study in respiratory care. Most (88.5\%) said they would be successful at completing their degrees if they decided to enroll in the MSRC program. While $92 \%$ believe that they are successful at taking undergraduate classes, only $27.5 \%$ think they will be good at research as the MSRC degree in the study site is research focused, and students are enrolled in at least one research course per semester during the MSRC program.

Participants' expectations and outcomes from graduate school This study assessed the outcomes students expect to achieve as they complete tasks and develop their skills in an academic degree program. For $98.9 \%$ of survey participants, they believe that graduate school will create more opportunities for employment. However, 24.1\% also thought that having an MSRC degree would make them overqualified to work in the profession (Table 2). Most students (67.8\%) consider the only difference between graduate classes and undergraduate classes to be the level of academic difficulty; approximately $58.6 \%$ believe that success in graduate school depends significantly on research skills. As shown in Figure 1, the top three reasons for attending graduate school are obtaining an advanced degree (54\%), the opportunity for increased earning ability (22\%), and personal interest (15\%). The last four are research opportunities $(3.4 \%)$, solely personal challenge $(2.3 \%)$, other reasons not stated (2.3), and no interest (1.1\%).

\section{Participants' perceived barriers to attend graduate school}

Figure 2 shows perceived barriers when it comes to attending graduate school. Overall, $39.1 \%$ of participants agreed that affordability and funding is the greatest concern. The second most common reason for not attending graduate school was the tediousness of completing schoolwork (23\%). Additional reasons included marriage/family plans (11.5\%), lack of time (10.3\%), low/unqualifying grades $(4.6 \%)$, application rejection (2.3\%), and other reasons not listed (1.1\%). Eight percent of study participants did not perceive any barriers to graduate school.

Participants' perceived support to attend graduate school As previously stated, affordability was listed as the participants' main concern for attending graduate school, with $71 \%$ of participants unaware

TABLE 1

Demographics of students participating in this research

\begin{tabular}{lrr}
\hline & Juniors & Seniors \\
\hline Age (Mean \pm SD) & $22 \pm 2.9$ & $24 \pm 3.4$ \\
Gender & & \\
Female, n (\%) & $37(88)$ & $41(91)$ \\
Male, n (\%) & $5(12)$ & $4(9)$ \\
Ethnicity & & \\
Caucasian, n (\%) & $14(34)$ & $19(42)$ \\
African American, n (\%) & $5(11)$ & $19(42)$ \\
Hispanic, n (\%) & $17(41)$ & $2(7)$ \\
Asian/Pacific, n (\%) & $6(14)$ & \\
\hline
\end{tabular}


TABLE 2

Students' perceived self-efficacy and expectations/outcomes of graduate school

\begin{tabular}{|c|c|c|c|c|c|}
\hline \multirow[t]{2}{*}{ Question } & \multicolumn{5}{|c|}{ Likert scale*, \% (n) } \\
\hline & 1 & 2 & 3 & 4 & 5 \\
\hline \multicolumn{6}{|l|}{ Self-efficacy } \\
\hline My undergraduate education has prepared me to make a decision about attending graduate school. & $4.6(4)$ & $5.7(5)$ & $32.2(28)$ & $34.5(30)$ & $23.0(20)$ \\
\hline If I decided to go to graduate school, I would be successful in completing the master's degree & 0 & 0 & $11.5(10)$ & $32.2(28)$ & $56.3(49)$ \\
\hline I would be good at research & $12.6(11)$ & $21.9(19)$ & $37.9(33)$ & $21.9(19)$ & $5.7(5)$ \\
\hline I am successful at taking classes & 0 & 0 & $8(7)$ & $50.6(44)$ & $41.4(36)$ \\
\hline I understand what is involved in applying to graduate school & $24.1(21)$ & $31.0(27)$ & $26.4(23)$ & $11.5(10)$ & $6.9(6)$ \\
\hline \multicolumn{6}{|l|}{ Expectations and outcomes } \\
\hline Attending graduate school will create more opportunities for me & 0 & 0 & $1.1(1)$ & $24.2(21)$ & $74.7(65)$ \\
\hline Graduate school would be similar to my undergraduate program except with harder classes & $4.6(4)$ & $11.5(10)$ & $16.1(14)$ & $27.6(24)$ & $40.2(35)$ \\
\hline Having an MS degree would make me overqualified to work in the profession. & $41.4(36)$ & $18.4(16)$ & $16.1(14)$ & $18.4(16)$ & $5.7(5)$ \\
\hline Success in graduate school depends on one's ability to do research. & 0 & $5.7(5)$ & $35.6(31)$ & $37.9(33)$ & $20.8(18)$ \\
\hline
\end{tabular}

*Likert Scale: 1 = Strongly disagree, 2 = Disagree, $3=$ Neutral, $4=$ Agree, $5=$ Strongly Agree; $n=87$.

\section{FIGURE 1}

Students' perceived reasons for attending graduate school.

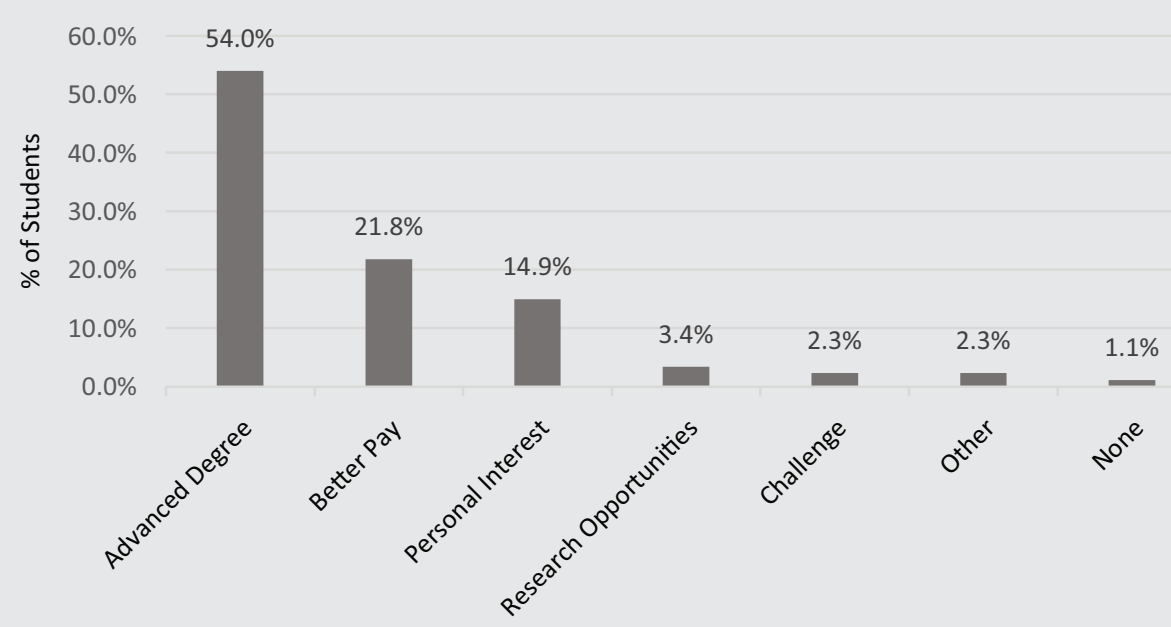

Reasons to Attend Graduate School

of any resources or financial support. Additionally, survey data showed that $67.8 \%$ of participants stated that one of their professors encouraged them to attend graduate school, and $19.5 \%$ discussed graduate school with current graduate students. Only $25.6 \%$ had a positive interaction with graduate students.

Participants' career goals

Goals are defined as choices that individuals make concerning their future ideas or plans. Participants agree that their undergraduate education has equipped them for their profession, and only $11.5 \%$ of participants believe that a graduate degree is required for the job they want. Approximately half of the survey participants plan on attending graduate school for their careers. Twenty-six percent believe that a graduate degree is only used by persons seeking to become professors. Of those interested in pursuing an advanced degree, not all plan to remain in the respiratory therapy field. Most participants reported interest in pursuing a master's degree in respiratory care, but participants also showed an interest in Physician Assistant, Business Administration, and Doctoral Degree programs in descending order. Most participants reported that if they were to attend graduate school, that it would be with their alma mater and would begin courses either immediately following or within 3 years of graduation. Finally, 18\% of participants stated they were not interested in attending graduate school.

\section{DISCUSSION}

This is the first study to assess undergraduate respiratory care students' perceived self-efficacy, expectations, barriers, and support for enrolling in a master's degree program in respiratory care. The current study is integral to our understanding of the motivations and deterrents of undergraduate respiratory care students toward pursuing graduate education in respiratory care. Consistencies between our results and the available literature were identified within the scope of graduate education. Self-efficacy, first conceptualized by Bandura [23] in 1977, maintains that "...people process, weigh and integrate diverse sources of information concerning their capability, and they regulate their choice behavior and effort expenditure accordingly" (p. 212). The majority of the students participating in the current project agreed or strongly agreed with three items covering self-efficacy. They believed (i) their undergraduate education preparation was sufficient to decide on graduate school, (ii) they 


\section{FIGURE 2}

Students' perceived barriers to attending graduate school.

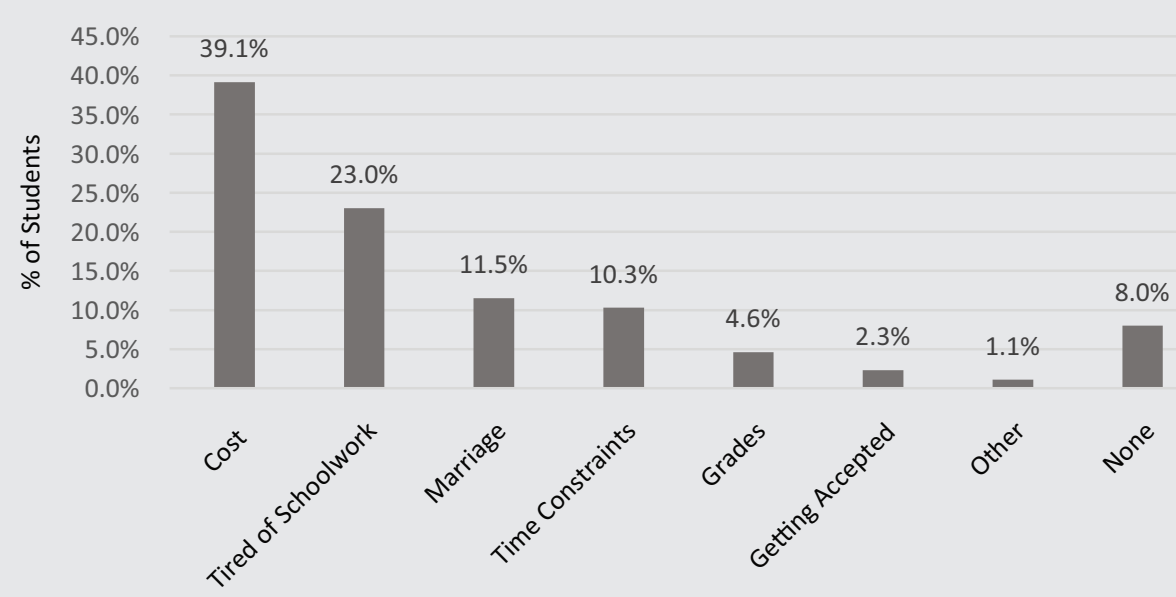

Barriers to Attend Graduate School

would be successful in graduate school, and (iii) they are successful when taking college classes.

Two items that threatened self-efficacy related to understanding what is involved in applying to a program and conducting research. Improvements in graduate program application instructions and communications between students and graduate program coordinators may improve students' self-efficacy for applying to graduate programs. Research skills and abilities appear to be an essential component influencing self-efficacy and graduate school enrollment. Tate et al. [24] investigated college students' pursuit of graduate education and, "...when students' self-efficacy for conducting graduate-level research increased, so did their active pursuit of graduate school" (p. 435). It is reasonable to believe that most science and medicine graduate programs have significant research requirements. Graduate school courses tend to consist of reading, critically assessing research articles, conducting independent research, discussing findings, and writing academic papers to meet the requirements of the graduate program. Therefore, if an undergraduate student has not engaged in research activities or lacks confidence in their skills, it will likely influence their pursuit of advanced degrees. According to the Commission on Accreditation for Respiratory Care (CoARC), all accredited respiratory care programs must include research experiences within the curriculum [25]. However, the specific content covered in that research requirement may not be sufficient to increase self-efficacy belief for the student. Our results indicate undergraduate research self-efficacy could be improved for the current participants by ensuring early exposure and development of even basic or introductory research abilities and academic writing skills.

Expectations and outcomes associated with attending graduate school were the second topics addressed in this study. It includes the efforts required to complete the degree and the impact that the degree will have on future success [26]. Results on this content indicate three areas with higher percentages in the "agree" and "strongly agree" categories and one area with a higher percentage in the "disagree" category. Specifically, most participants appear to "agree" or "strongly agree" that (i) graduate school will create more opportunities, (ii) the graduate curriculum will be harder than the undergraduate content, and (iii) research ability would influence success in graduate school. The survey suggests participants do not believe that a graduate degree in respiratory care will make them overqualified to work in the profession. Undergraduate respiratory care students appear to appreciate the value of advanced education in the discipline.
In 2011, there was support for additional respiratory care faculty with graduate degrees, teaching and presentation experience, and scholarly activity to fill vacant and soon-to-be-vacant respiratory care positions [27]. A similar sentiment was also expressed by the Institute of Medicine in 2011 regarding the nursing profession [27]. Munoz [28] stated, "The health of our nation's citizens depends on more nurses attending graduate school, so they can provide higher levels of patient care, educate future nurses, and conduct research for the benefit of the population at large" p. 112. Though this discusses the nursing field, this notion is applicable to all health care disciplines, including respiratory therapy.

Barriers to attending graduate school included the cost of additional schooling, and accruing additional college debt was a major concern. Borrego et al. [22] similarity identified cost as a barrier that decreased the likelihood of enrolling in a graduate program, and without any financial support this can be a hindrance to seeking an advanced degree. Although tuition and fee costs are set by the university administration and not controlled by most programs, there are funding opportunities available to assist with school expenses. Unknown to participants, a number of financial supports are available to graduate students, such as student loans, numerous grants, and scholarships both public and private, that can be used to support academic pursuits.

Another challenge exists in the lifestyle realities of many graduated students, as they may simultaneously be in full-time working positions. Therefore, tuition reimbursement opportunities offered by employers need to be explored and communicated to potential applicants. Most participants $(67.7 \%)$ surveyed reported that one of their professors encouraged them to attend graduate school. Still, any measurable impact these student and faculty conversations will have on enrollment is unable to be determined in this study. Bandura [23], however, understood the influence these interactions can have and theorized that "... expectations of personal efficacy are derived from four principal sources of information: performance accomplishments, vicarious experience, verbal persuasion, and physiological states" (p. 191). Faculty role models and verbal persuasion can influence self-efficacy to encourage students to further their education and be a prime motivator for students to pursue advanced degrees

Career goals may also influence student decisions to pursue graduate degrees. This study determined that this undergraduate respiratory care student cohorts' primary goal is to become registered respiratory therapists (RRT) and obtain employment as active, practicing professionals in a health care organization. At this point, students may not yet aspire to 
careers beyond the entry-level point, and therefore the opportunities afforded by a graduate education are not recognized. Only $11.5 \%$ of the participants believed a graduate degree is required for the job they want. It is fair to conclude most participants do not envision obtaining an advanced level position (leadership, research, academe) in the immediate future, even if obtaining a graduate degree could be fortuitous for these young professionals, as there are numerous publications attesting to the salary benefits resulting from an advanced degree. The Bureau of Labor Statistics publishes data on educational attainment and earnings, which project a higher level of education translates to higher earnings [29].

Another encouraging result from this survey was the level of interest in graduate programs, of which most participants favored a graduate degree in respiratory care. Even though we cannot expect all undergraduate students to pursue an advanced degree in the same field, it is promising from a professional advancement perspective to know that students with interest would consider that MSRC degree within the profession rather than one in a differing field.

\section{Implications of the study}

Matriculating into graduate school is an important decision for an undergraduate student, so understanding their perceptions of graduate school have several implications for graduate program coordinators. First, self-efficacy toward research abilities will undoubtedly influence the enrollment decisions of prospective students. In most cases, a graduate program coordinator is unable to influence research experiences gained in the undergraduate program; however, knowing the baseline expectations of research self-efficacy a potential among applicants will aid in directing time and efforts in improving preparedness for research studies. Also, sharing graduate program research curriculum and expectations with undergraduate respiratory care programs may provide a mechanism for improving research self-efficacy through the early introduction of concepts and development of basic skills. It is understandable to have doubt about research abilities during undergraduate schooling, but it should not deter the desire of those that wish to pursue enrollment. Second, awareness of the barriers to enrollment will allow program coordinators to improve accessibility and address these challenges through curriculum sequencing, such as creating part-time enrollment, providing information sessions to answer questions, or organizing orientation days to provide application advise and information. Current and former graduate students can share experiences and reassure potential applicants of the requirements and time commitments, which would additionally provide opportunities for networking and professional interaction. For those concerned with financial assistance, a discussion of university resources and scholarship opportunities will allow potential applicants to appreciate the financial commitments an institution makes toward a student's education. Lastly, recruiting undergraduate students into a graduate program is a continuous goal since a steady flow of new applicants is critical to program viability. Individual academic programs are expendable if low enrollment and the cost to sustain the program interfere with the university operations. Therefore, the cancellation of a degree program is an unfortunate reality. Program coordinators and recruiting specialists must actively engage undergraduate students and sell the benefits of advanced education since recruitment cannot happen solely by chance. Graduate programs serve both the profession and the individual equally. In the current landscape of aging educators, developing future, qualified undergraduate faculty is paramount. Respiratory care programs require faculty that are veterans and vastly experienced in the field of respiratory care. Prior to graduate degrees in respiratory care, those that wished to obtain faculty positions were required to complete graduate degrees outside of the discipline. Outside of academe, a graduate degree in respiratory care is still valuable. Department directors, consultants, clinical educators, product specialists, and managers of clinical affairs positions represent possible job opportunities that utilize graduate degrees in respiratory care. Students' needs and perceptions must be considered during the development and promotion of graduate respiratory care education. Failure to understand students' perceptions will create challenges to enrollment and decrease student interest in MSRC programs. Regardless of the barrier, a plan to address the obstacle and find a solution is important.

\section{Limitations of the study}

Some limitations do exist with this study. Participants were recruited from a single respiratory care program in the United States. An expanded study involving other programs throughout the United States would increase the generalizability of the findings. In addition, this study only captured perceptions from respiratory care students in the United States. Surveying non-U.S. respiratory care students on their perceptions of graduate education is warranted. Future studies could be expanded to other countries to capture and compare perceptions within and between environments. The sample size was relatively small in our study. Our sample size was similar to the number of participants for the Borrego et al. study [22]. However, expanding the number of data sites and increasing the number of participants would increase the representativeness of the data to the worldwide respiratory care community.

\section{CONCLUSION}

This study takes a first look at undergraduate respiratory care student perceptions of enrolling in a master's degree program. We believe this study contributes valuable data related to prospective students' plans for future educational advancement. There is a measurable interest among participants to pursue graduate studies in respiratory care. At the time of this writing, graduate degrees in respiratory care included entry-to-practice degrees and post-professional degrees. The focus of this study was on students' perceptions on advancing to a post-professional graduate degree in respiratory care. Future research needs to be completed to elucidate the deeper meaning of the survey data and expand the inquiry to a larger group of undergraduate respiratory care students.

\section{DISCLOSURES}

\section{Conflict of Interest}

Dr. Ari discloses her relationship with Aerogen Ltd and Philips Healthcare. The rest of the authors have no conflict to disclose.

\section{Author's Contributions}

Dr. Ari conceived of the idea of this research project. Mr. Showalter searched the literature, prepared the survey, and conducted the study. Dr. Ari and Mr. Showalter performed data analysis. Dr. Ari, Dr. Russian, and Dr. Gonzales drafted the manuscript. All authors reviewed and revised the manuscript. They also approved the final draft before submission.

\section{Ethical Approval}

This study was approved by the institutional review board at Texas State University. The survey was completely anonymous, and participation was voluntary.

\section{REFERENCES}

1. Barnes TA, Kacmarek RM, Kageler WV, Morris MJ, Durbin CG. Transitioning the respiratory therapy workforce for 2015 and beyond. Respir Care 2011;56(5):681-90. doi: 10.4187/respcare.01169

2. American Association for Respiratory Care. American Association for respiratory care human resources survey-2017. Dallas, TX: AARC; 2017.

3. Becker ES. Respiratory care managers' preferences regarding baccalaureate and master's degree education for respiratory therapists. Respir Care 2003;48(9):840-58.

4. American Association for Respiratory Care. American Association for Respiratory Care Human Resources Survey-2000. Dallas, TX: AARC; 2001.

5. Sperle CK. Predictors of success in a baccalaureate respiratory therapy program. Respir Care Educ Annu 2014;23:28-33.

6. Helton PR, Gresham-Anderson JL, Case RD, Judy EL. Career intentions of degree advancing respiratory therapist: a mixed method study. Respir Care Educ Annu 2020;28:13-23.

7. Koster MS, Wing TJ. Admission criteria and course performance in an undergraduate respiratory care program: a case for non-cognitive measures. Respir Care Educ Annu 2019;28:3-17. 
8. Galvin WF. Associate in science degree education programs: organization, structure, and curriculum. Respir Care Clin N Am 2005;11(3):383-400. doi: 10.1016/j.rcc.2005.04.009

9. Becker EA, Nguyen XT. The current impact of entry-level associate and baccalaureate degree education on the diversity of respiratory therapists. Respir Care 2014;59(12):1817-24. doi: 10.4187/respcare.03106

10. Ari A, Goodfellow LT, Rau JL. Characteristics of a successful respiratory care education program. Respir Care Clin N Am 2005;11:371-81. doi: $10.1016 /$ j.rcc.2005.04.010

11. Case RD. The effectiveness of interprofessional simulation experiences used in health sciences education. Respir Care Educ Annu 2020;29:3-12.

12. Oppermann RE, Sergakis GG, Varekojis SM. Improving critical thinking skills of undergraduate respiratory therapy students through the use of a student-developed, online respiratory disease management database. Respir Care Educ Annu 2020;29:24-33.

13. Vernon MM, Moore NM, Cummins L-A, et al. Respiratory therapy faculty knowledge of and attitudes toward interprofessional education. Respir Care 2017;62(7):873-81. doi: 10.4187/respcare.05034

14. Ari A, Gardenhire D, Goodfellow L. Identifying the variables of grading practices that influence students' evaluation of clinical instructors. Respir Care Educ Annu 2006;15:31-9.

15. Ari A, Goodfellow LT, Rau JL. Quality of instructions and teaching effectiveness in clinical respiratory care education. Respir Care Educ Annu 2003;12:3-9.

16. Alghamdi SM, Ari A. Evaluation of the clinical learning environment in respiratory therapy education: student perceptions. Respir Care 2019;64(2):161-8.

17. Ari A, Goodfellow L, Gardenhire D. Admission criteria as predictors of student performance on the national board for respiratory care exami nations. Respir Care Educ Annu 2008;17:1-6.

18. Ari A. Connecting students to institutions: the role of program resources on stud ent retention in respiratory care education programs. Respir Care 2009; 54(9):1187-92.
19. Ari A. A study of program effectiveness: the relationship between program resources and program performance on the written registry for respiratory care examination. Respir Care Educ Annu 2007;16:39-48.

20. Ari A, Atalay OT, Aljamhan E. From admission to graduation: the impact of gender on student academic success in respiratory therapy education. J Allied Health 2010;39(3):175-8.

21. Ari A. Implementing computerized patient simulations as a measure of student learning on patient management in respiratory therapy education. Respir Care Educ Annu 2011;20:11-16.

22. Borrego MJ, Knight DB, Gibbs K, Crede ED. Pursuing graduate study: underlying undergraduate engineering students' decisions. Res J Eng Educ 2018;107(1):140-63.

23. Bandura A. Self-efficacy: toward a unifying theory of behavioral change. Psychol Rev 1977;84(2):191-215.

24. Tate KA, Fouad NA, Marks LR, Young G, Guzman E, Williams EG. Underrepresented first-generation, low-income college students' pursuit of a graduate education: investigating the influence of self-efficacy, coping efficacy, and family influence. J Career Assess 2015;23(3): $427-41$.

25. Commission on Accreditation for Respiratory Care (COARC). Accreditation standards for the entry into respiratory care professional practice. 2020. Available at: https://www.coarc.com/Accreditation/ Entry-into-Practice-Standards.aspx (Accessed July 12, 2021).

26. Barnes TA, Kacmarek RM, Durbin CG. Survey of respiratory therapy education program directors in the United States. Respir Care 2011;56(12):1906-15.

27. Institute of Medicine. The future of nursing: leading change, advancing health. Washington, DC: The National Academies Press. 2011.

28. Munoz LR. Graduate student self-efficacy: implications of a concept analysis. J Prof Nursing 2021;37:112-21. doi: 10.1016/j.profnurs.2020.07.001

29. Bureau of Labor Statistics. Unemployment rates and earnings by educational attainment, 2019. Available at: https://www.bls.gov/emp/chart-unemployment-earnings-education.htm (Accessed March 14, 2021). 